\section{A NATUROLOGIA NO BRASIL: AVANÇOS E DESAFIOS}

\section{THE NATUROLOGY IN BRAZIL: DEVELOPMENTS AND CHALLENGES}

\section{RESUMO}

A naturologia é uma profissão recente no Brasil, a qual busca entender o ser-humano multidimensionalmente e respeitar a singularidade humana na busca de bem-estar, qualidade de vida e saúde através da relação de interagência e das Práticas Integrativas e Complementares. Este dossiê aborda um breve histórico das Práticas Integrativas e Complementares e Naturologia no Brasil, o processo de reconhecimento da ocupação e regulamentação da profissão. $O$ texto também explora os campos de atuação do naturólogo, órgãos de representação profissional, principais eventos científicos e publicações importantes da área. Por fim, são apresentados documentos importantes: Aprovação do MEC dos cursos existentes, Carta de Intenção de abertura de curso superior de Naturologia por uma Universidade Federal, Editais de concursos públicos, Relatos de experiências de trabalhos de Naturólogos em instituições de renome nacional, Anais dos Congressos Brasileiros de Naturologia e Carta da Pedra Branca, a qual traça diretrizes futuras para a Naturologia no Brasil.

\section{PALAVRAS-CHAVE}

Naturologia.

Práticas Integrativas e Complementares.

História.
Silvia Helena Fabbri Sabbag - Naturóloga formada pela UAM

- Diretora Social da APANAT

Beatriz Mendes Reis Nogueira

- Graduanda em Naturologia pela UNISUL

- Secretária da ABRANA

Andrea Lucila Lanfranchi De Callis - Graduanda em Naturologia pela UAM

Ana Claúdia Moraes Barros Leite-Mor

- Naturóloga formada pela UNISUL

- Mestranda em Saúde Coletiva pela UNICAMP

Caio Fábio Schlechta Portella

- Naturólogo formado pela UAM.

- Mestrando em Saúde Pública pela USP

Raquel de Luna Antônio

- Naturóloga formada pela UAM

- Mestre e doutoranda em Psicobiologia pela UNIFESP

Flavia Placeres

- Naturóloga formada pela UAM

- Presidente da APANAT

Daniel Maurício de Oliveira Rodrigues

- Naturólogo formado pela UNISUL

- Mestre em Saúde Coletiva pela UFSC

CORRESPONDENTE

Daniel Maurício de Oliveira Rodrigues

Curso de Naturologia,

Universidade do Sul de Santa Catarina

Av. Pedra Branca, $n^{\circ} 25$

Palhoça - SC

danielmor7@gmail.com

Recebido: 05/04/2013

Aprovado: 11/05/2013 


\begin{abstract}
Naturology is a new profession in Brazil, one which seeks to understand the human being in a multi-dimensional way, and respect human singularity in its search for well-being, quality of life and health through a relationship of interagency and Complementary and Integrative Practices. The present dossier addresses a brief history of Complementary and Integrative Practices and Naturology in Brazil, the process of recognizing the occupation and regulation of the profession. The paper also explores the fields in which the naturologist is active, the bodies of professional representation, the main scientific events and important publications in the field. Finally, important documents are presented: the approval by the Brazilian Ministry of Education (MEC) of the existing courses, Statement of Purpose for opening undergraduate-level major in Naturology by a Federal University, notices for public tendering, Proceedings of Brazilian Naturology Conferences and the Charter of Pedra Branca, which sets future guidelines for Naturology in Brazil.
\end{abstract}

KEY WORDS: Naturology. Complementary and Integrative Practices. History.

\section{INTRODUÇÃO}

A Naturologia é orientada pelas áreas de humanas, biológicas e da saúde, tendo como ideal abordar o indivíduo de maneira multidimensional, levando em consideração aspectos físicos, emocionais, mentais, ambientais, culturais, espirituais, sociais. A proposta de intervenção é desenvolver e ampliar a auto-reflexão, o auto-conhecimento e o auto-cuidado. Para tanto, utiliza-se uma abordagem de educação em saúde que desenvolve o entendimento da co-responsabilidade do indivíduo frente à sua saúde, qualidade de vida e bem-estar. Este profissional trabalha com uma perspectiva do cuidado humanizado, da escuta acolhedora, do desenvolvimento do vínculo terapêutico e preconiza a autonomia do sujeito ${ }^{15}$.

Este dossiê objetivou demonstrar os avanços e desafios da Naturologia no país. Inicialmente é abordado a história do Sistema Único de Saúde, das Práticas Integrativas e Complementares no Brasil. Os autores citam alguns locais que os naturólogos atuam ou atuavam, contextualizam fatos políticos importantes como a criação do Dia do Naturólogo em São Paulo e Florianópolis, projetos de lei de regulamentação da profissão e 0 andamento atual do último projeto apresentado a Câmara Federal dos Deputados.

O texto também explora definições de Naturologia, como é abordagem profissional e quais os campos de atuação do naturólogo. Os autores descrevem estudos sobre a situação profissional dos naturólogos no Brasil, citam os órgãos de representação profissional e os principais eventos científicos e publicações importantes da área. São apresentados documentos importantes como Aprovação do MEC dos cursos existentes de Naturologia na Universidade do Sul de Santa Catarina e Anhembi Morumbi, Carta de Intenção de abertura de curso superior de Naturologia pela Universidade Federal do Paraná - Campus Litoral e Editais de concursos públicos para naturólogos em sete cidades brasileiras. Por fim, o manuscrito cita dois Relatos de experiências de trabalhos de Naturólogos em instituições de renome nacional, Anais dos Congressos Brasileiros de Naturologia e a Carta da Pedra Branca, a qual traça diretrizes futuras para a Naturologia no Brasil.

\section{A HISTÓRIA DO SISTEMA ÚNICO DE SAÚDE NO BRASIL}

A Constituição Federal Brasileira, em 1988, ao decretar a saúde como direito de todos e dever do Estado, responde ao movimento popular organizado que requeria há duas décadas um sistema de saúde universal e gratuito. É instituído, então, o Sistema Único de Saúde - SUS como rede regionalizada e hierarquizada que responde pelas ações de promoção, proteção e recuperação da saúde com acesso integral, universal e igualitário ${ }^{1}$ São princípios do SUS:

I - descentralização, com direção única em cada esfera de governo;

II - atendimento integral, com prioridade para as atividades preventivas, sem prejuízo dos serviços assistenciais; 
III - participação da comunidade

Desta forma, em 1990 é sancionada a Lei Orgânica da Saúde (Lei 8080/90), que dispõe sobre as condições para a promoção, proteção, e recuperação da saúde, assim como a organização e funcionamento dos serviços correspondentes. Estas conquistas legais representam um grande avanço para a democratização da saúde no Brasil, tanto ao garantir atenção à saúde como direito constitucional, quanto ao instituir a participação popular como integrante nos processos deliberativos e administrativos do sistema de saúde ${ }^{2}$

\section{HISTÓRICO DAS PRÁTICAS INTEGRATIVAS E COMPLEMENTARES NO BRASIL}

Na década de 70, com o desenvolvimento científico e tecnológico, a assistência na área da saúde seguiu rumo à mecanização, reducionismo, especialização e tecnificação, em detrimento da visão do homem como um ser integral, que considera os aspectos físicos, psicológicos, mentais, emocionais, ambientais e sociais de cada indivíduo ${ }^{3}$.

Como marco histórico da democratização da saúde e valorização de outras abordagens no cuidado com a saúde no país, ocorreu, em 1986, a $8^{\text {a }}$ Conferência Nacional de Saúde - a primeira conferência aberta à participação popular e da sociedade civil organizada. Nesta conferência já é requerida " $a$ introdução de práticas alternativas de assistência à saúde no âmbito dos serviços de saúde, possibilitando ao usuário o acesso democrático de escolher a terapêutica preferida”. Logo, pelo fortalecimento das Práticas Integrativas e Complementares - PIC e sua implementação no SUS, o movimento tem o caráter de pluralização e democratização dos sistemas e instituições de atenção à saúde ${ }^{4}$. Paralelamente, a Organização Mundial de Saúde - OMS, com o Programa de Medicina Tradicional, reconhece e incentiva em diversas publicações a prática de Medicinas Tradicionais e Práticas Integrativas e Complementares. No Brasil, é publicada, em 2006, pelo Ministério da Saúde - MS, a Política Nacional de Práticas Integrativas e Complementares - PNPIC, a qual formaliza e incentiva a implementação dessas práticas no Sistema Único de Saúde - SUS.A PNPIC contempla sistemas médicos complexos e recursos terapêuticos, os quais são também denominados pela Organização Mundial de Saúde - OMS de Medicina Tradicional e Complementar/Alternativa - MT/MCA ${ }^{5}$.

Tais sistemas e recursos envolvem abordagens que buscam estimular os mecanismos naturais de prevenção de agravos e recuperação da saúde por meio de tecnologias eficazes e seguras, com ênfase na escuta acolhedora, no desenvolvimento do vínculo terapêutico e na integração do ser humano com o meio ambiente e a sociedade ${ }^{5}$.

\section{SURGIMENTO DA NATUROLOGIA NO BRASIL}

Em meados de 1990, aumenta a preocupação em fundamentar e aprimorar o uso e o estudo dos tratamentos tradicionais, complementares e integrativas que, até o momento, englobavam um grupo disperso, em resposta à crescente procura por tais práticas $^{6}$.

A partir da exigência do mercado e demandas públicas originadas na constituição do SUS, surge o Bacharelado em Naturologia no Brasil, constituindo uma formação de nível superior para atuar com as PIC . » 1994 - Faculdade de Ciências Biológicas e da Saúde Doutor Bezerra de Menezes - Curitiba cria o curso técnico em Naturologia.

» 1998 - UNISUL - Universidade do Sul de Santa Catarina - Florianópolis; (ANEXO I) cria o primeiro curso superior (Bacharelado) de Naturologia do país. » 2002 - Universidade Anhembi-Morumbi, em São Paulo; (ANEXO II) cria o segundo curso de Naturologia. »2012 - Universidade Federal do Paraná (ANEXO III) - manifesta interesse em abrir o curso de Bacharelado em Naturologia.

Com a formação de naturólogos e o ingresso no mercado de trabalho, surgem as associações ABRANA (2004) e APANAT (2007), com o objetivo de divulgar a Naturologia e dar suporte aos profissionais naturólogos ${ }^{7-8}$.

Em levantamento realizado em janeiro de 2013 pelo naturólogo Bruno Werneck (ANEXO IV), sete 
cidades brasileiras possuem serviços de saúde com naturólogos concursados, sendo três cidades no Estado de Santa Catarina (duas vagas no município de São Joaquim, uma em Ermo e uma em Laguna), duas cidades no Estado de São Paulo (uma vaga em Registro e uma em Santa Gertrudes), uma no Estado do Rio de Janeiro (uma vaga em Macaé) e uma em Rondônia (uma vaga em Vilhena) 9 .

Além destes cargos de servidores públicos, podem-se citar outros locais de destaque onde o profissional de Naturologia atuou ou atua. Estão na sequência.

\section{Setor Público}

»Ambulatório de Iridologia da USP (São Paulo - SP)

»Assembleia Legislativa do Estado de Santa Catarina - ALESC

»Casa da Criança e do Adolescente (Estado do Rio de Janeiro)

»Casa do Adolescente (São Paulo - SP)

»Centro Cultural Cândido Ferreira / FUMEC e prefeitura de Campinas (Campinas - SP)

»Centro de Atenção Psicossocial

- CAPS (Palhoça - SC)

»Centro de Estudos do Envelhecimento / UNIFESP (São Paulo - SP)

»Centro de Pesquisas Químicas, Biológicas e Agrícolas da UNICAMP / Setor de Microbiologia (Campinas - SP)

»Centro de Referência da Saúde do Trabalhador

- Poços de Caldas (MG) (ANEXO V)

»Centro de Referência da Saúde do Trabalhador - Santos (SP)

»Centro Dia do Idoso - Prefeitura Municipal de Rio Claro (SP)

»Escolas Municipais de Macaé (RJ)

»Estado do Rio de Janeiro (LEI No 5471, DE 10 DE JUNHO DE 2009) - Programa de Terapia Natural para o atendimento da população do Estado do Rio de Janeiro

»Hospital das Clínicas - Saúde do Adolescente - SP (ANEXO VI)

» Hospital de Caridade (Florianópolis - SC)

» Hospital Pérola Byington -

(São Paulo - SP) (ANEXO VI)

»Hospital Psiquiátrico Vera Cruz (São Paulo - SP)

»Hospital Universitário - HU (Florianópolis - SC)
» Núcleo de Apoio à Saúde da Família

- NASF (Biguaçu - SC)

»Projeto Amanhecer - UFSC (Florianópolis - SC)

»Projeto Plantas Medicinais / Hidrelétrica de Itaipu Binacional (Bacia do Paraná - PR)

»Setor de Transdisciplinar Aplicada a

Saúde / UNIFESP (São Paulo - SP)

»UBS Eloy Chaves (Jundiaí - SP)

»Unidade Básica de Saúde Brejaru (Palhoça - SC)

»Unidade Básica de Saúde Jardim

Eldorado (Palhoça - SC)

»Unidade Básica de Saúde de São Joaquim - SC

»Unidade Básica de Saúde de Tijucas - SC

\section{Setor Privado}

»Hospital Albert Einstein - SP

»Hospital São Luiz - Maternidade - SP

\section{Terceiro Setor}

»APAE (Santo Amaro - SC)

»APAE (São José - SC)

»Asilo Centro Vicentino Nossa Senhora das Dores (Araçoiaba da Serra - SP)

»Associação Catarinense de Integração dos Cegos - ACIC (Florianópolis - SC)

»Associação Cristã Beneficente dos Coreanos da América do Sul (São Paulo - SP)

»Associação Desportiva dos Deficientes - ADD (São Paulo - SP)

»Associação Morungaba (São Paulo - SP)

»Casa Eliane de Grammont (São Paulo - SP)

»Lar Escola Monteiro Lobato (Sorocaba - SP)

»ONG Cahon (Sorocaba - SP)

»ONG Casa do Zezinho (São Paulo - SP)

»ONG GAIA / Grupo de Apoio ao Idoso à Infância e à Adolescência (São Paulo - SP)

Em 2004, foi instituído, no âmbito do Município de São Paulo, o Dia do Naturólogo, a ser comemorado, anualmente, em 23 de março, através do Projeto de Lei $n^{\circ}$ 503/04, apresentado pelo vereador Celso Jatene $^{10}$. $\mathrm{O}$ município de Florianópolis, através do projeto enviado pelo vereador Jaime Tonello (PSD), instituiu a Lei Municipal $n^{\circ} 1.015 / 2012$, publicada no Diário Oficial no 773, de 27 de julho de 2012, que comemora nesta mesma data o Dia do Naturólogo ${ }^{11}$. 
As associações de Naturologia estão trabalhando para regulamentar a profissão de naturólogo. Em meados de 2005, foi entregue o primeiro Projeto de Lei através do Deputado Professor Irapuan Teixeira (PP-SP), com o número PL 5257/05, mas este teve seu andamento interrompido devido à saída do Deputado. Depois, em 14 de setembro de 2009, a APANAT representada por Suely Ramos Bello e Glicia Fonseca de Oliveira e a ABRANA representada por André Werlang Garcia e Jackson Diogo S. Souza entregaram ao Deputado Federal Cláudio Vignatti (PT-SC) o Projeto de Lei para regulamentar a profissão de Naturólogo, ao qual não foi dado andamento.

Em 26 de março de 2012, as Associações, representadas por Kalil Mondadori (ABRANA) e Flavia Placeres (APANAT), entregaram o Projeto de Lei para a Regulamentação da Profissão de Naturólogo ao Deputado Federal Giovani Cherini no $7^{\circ}$ Encontro Estadual de Terapeutas e Profissionais Holísticos no Palácio Farroupilha, em Porto Alegre, Rio Grande do Sul. Em 03 de maio de 2012, foi apresentado, na Câmara dos Deputados, o Projeto de Lei 3804/2012, de autoria do Deputado Giovani Cherini (PDT-RS) que regulamenta a profissão de Naturólogo ${ }^{\text {II }}$.

O Projeto de Lei 3804/2012 regulamenta a profissão de naturólogo e lista a definição da atividade bem como as suas competências. Determina as condições para o exercício profissional: os possuidores de diploma de nível superior (Bacharelado) de Naturologia, expedido por instituição autorizada e reconhecida pelo governo federal. A iniciativa é justificada pela necessidade de regular a prática profissional e qualidade na formação daqueles que praticam a Naturologia, notoriamente benéfica à saúde humana, quando suas práticas são aplicadas por profissional capacitado, várias das quais, inclusive, reconhecidas pela Organização Mundial da Saúde, que as admite e estimula nos sistemas de saúde, de forma integrada às técnicas modernas da medicina convencional.

Atualmente o PL 3804/2012 teve parecer favorável do relator na Comissão de Seguridade Social e Família (CSSF) e por enquanto permanece nesta comissão até a aprovação da mesma, quando então passará pela Comissão de Trabalho, de Administração e Serviço Público (CTASP); se aprovado, passará pela Comissão de Constituição e Justiça e de Cidadania (CCJC). Após este processo, o Projeto de Lei será votado na Câmara dos Deputados.

Em 21 de novembro de 2012, foi protocolado um ofício o qual solicitava ao Conselho Nacional de Saúde (CNS) a inserção/incorporação do Naturólogo como profissional da saúde (hoje são apenas 14 profissões listadas pelo CNS). 0 protocolo gerou o número SIPAR 250000206662/2012 e pode ser consultado no site <sipar.saude.gov. br $>$. Nesta mesma data, a entidade nacional representante dos naturólogos, ABRANA, colheu informações, para termos um membro efetivo na Comissão Intersetorial de Práticas Integrativas e Complementares - CIPIC.

Em 2011, foi dada a entrada para o reconhecimento da profissão no Ministério do Trabalho, através da Classificação Brasileira de Ocupações - CBO. Aprovado, garantirá que o Naturólogo trabalhe em regime de CLT.

\section{DEFINIÇÃO DE NATUROLOGIA}

É reconhecida hoje a insuficiência do modelo cartesiano-biomédico em responder à complexidade do fenômeno saúde-doença. A Naturologia é fruto desta crise de paradigmas e procura responder a ela com uma visão integral do ser humano, formas terapêuticas mais acessíveis, provenientes de recursos naturais, e uma proposta ativa de promoção da saúde. Entende-se por visão integral $o$ respeito à complexidade do sujeito, reconhecimento da singularidade da experiência de saúde-doença e intervenção terapêutica igualmente sin$\operatorname{gular}^{12-13}$.

Pode-se definir Naturologia como conhecimento da área da saúde embasado na pluralidade ${ }^{\mathrm{III}}$ de sistemas terapêuticos complexos vitalistas ${ }^{\mathrm{IV}}$, que parte de uma visão multidimensional ${ }^{\mathrm{V}}$ do proces- $^{-}$ so de saúde-doença e utiliza da relação de interagência $^{\mathrm{VI}} \mathrm{e}$ de práticas integrativas e complementares no cuidado e atenção a saúde. 
Ela é produto de interações, religações e diálogos entre práticas e sistemas terapêuticos como as medicinas tradicionais e os conhecimentos biológicos e biomédicos da ciência moderna ${ }^{14}$. O conhecimento do naturólogo é orientado pelas ciências biológicas, humanas, sociais e também advindo de racionalidades terapêuticas vitalistas ${ }^{\mathrm{VII}}$, de modo a promover, manter ou melhorar a qualidade de vida e o bem-estar dos indivíduos ${ }^{13-14}$.

\section{ABORDAGEM DO NATURÓLOGO}

Partindo de um olhar multidimensional do ser-humano e considerando aspectos físicos, emocionais, mentais, espirituais, ambientais e sociais, a Naturologia propõe atenção à saúde com base no cuidado humanizado e intervenções que visam desenvolver e ampliar a autorreflexão, $\mathrm{o}$ autoconhecimento e $\mathrm{o}$ autocuidado de seu paciente/interagente ${ }^{15}$.

Este modelo de relação é denominado interagência, e nele o naturólogo age como um facilitador do processo de restabelecimento do equilíbrio e, consequentemente, da saúde ${ }^{16}$.

\section{CAMPO DE ATUAÇÃO DO NATURÓLOGO}

O naturólogo atua no âmbito privado e público, com atendimentos individuais na saúde do adulto, da criança, do idoso e da gestante associado, ou não, a equipes multidisciplinares. Trabalha, também, em consultoria na área da saúde, projetos de promoção e educação em saúde, em pesquisa científica e com gestão de equipes/serviços de saúde relacionados à PIC $^{3}$.

Os locais de atuação deste profissional têm sido diversificados: Spas, estâncias hidrominerais, ONGs, clínicas de estética, clínicas multiprofissionais no âmbito privado e Unidades Básicas de Saúde, Centro de Atenção Psicossocial - CAPS, policlínicas e hospitais no cuidado paliativo e no pré e pós-operatório na área pública ${ }^{12}$.

Na Saúde coletiva, este profissional também trabalha com atividades de educação em saúde e vivências relacionadas às PIC visando a promoção da saúde e a integração social ${ }^{12}$.

\section{PRÁTICAS INTEGRATIVAS E COMPLEMENTARES}

»Aromaterapia - uso terapêutico de óleos essenciais extraídos de plantas ${ }^{17}$, visando afetar ou alterar o humor ou comportamento de uma pessoa, e facilitar o bem-estar físico, mental e emocional ${ }^{18}$. As propriedades terapêuticas da aromterapia têm sido utilizados historicamente na África, Ásia e Índia ${ }^{19}$. »Cromoterapia - terapia que utiliza a cor para influenciar a saúde e tratar várias desordens físicas ou mentais, baseando-se no efeito das diferentes frequências de luz (do espectro visível) nas vias neuro-hormonais humanas, precisamente nas vias de melatonina e serotonina no cérebro ${ }^{20}$. As cores são os comprimentos de ondas percebidos no espectro eletromagnético visível $(400-700 \mathrm{~nm})$, e podem ser irradiadas em zonas específicas da pele ou aplicados mentalmente através de sugestão ${ }^{13,19}$. » Fitoterapia - uso de plantas medicinais em suas diferentes formas farmacêuticas (infusões, decocções, emplastros e outros), sem a utilização de substâncias ativas isoladas, ainda que de origem vegetal ${ }^{5}$. »Florais - terapêutica que utiliza essências de flores para atuar nos estados mentais e emocionais ${ }^{13}$; »Geoterapia - terapia através da argila/barro medicinal ${ }^{13}$;

»Hidroterapia - aplicação externa e interna da água em diferentes temperaturas e formas para fins terapêuticos, podendo ser termais (termalismo) e minerais (crenoterapia) ${ }^{13,19}$

»Instrumentos de diagnose como Iridologia - Recurso diagnóstico baseado nas alterações do aspecto da íris, esclera e pupila do interagente ${ }^{19} \mathrm{e}$ técnicas de avaliação utilizadas pelas Medicinas Tradicionais Chinesa e Ayurveda;

»Massoterapia - conjunto de manipulações sistemáticas em tecidos corporais moles, a partir da pele, que estimula os sistemas imune e circulatório $^{21}$, nervoso ${ }^{22}$ e muscular ${ }^{23}$. Podem ser massagem sueca, Tyui-ná, Abyanga, Shiatsu, dentre outras);

»Meditação - trata-se de um treinamento mental da atenção, cujos benefícios influem a melhora de funções cognitivas e relaxamento ${ }^{24}$. Uma ampla varie- 
dade de técnicas são utilizadas para focar a mente ${ }^{19}$ »Práticas corporais baseadas nas Medicinas Tradicionais: Yoga, Tai Chi Chuan, Qi Gong, Liang Gong; » Reflexoterapia - terapia através dos pontos reflexos existentes no corpo, como nos pés, mãos e orelhas; » Terapias expressivas - utilização da arte, dos sons de instrumentos, da música, da dança no processo terapêutico;

» Trofoterapia - utilização de uma abordagem qualitativa na alimentação, incentivando a utilização de alimentos integrais e orgânicos ${ }^{13}$.

\section{SITUAÇÃO PROFISSIONAL DO NATURÓLOGO NO BRASIL}

Segundo o levantamento realizado por Conceição e Rodrigues $^{25}$ em 2011, estima-se que haja $2.000 \mathrm{Na-}$ turólogos formados no Brasil e cerca de 500 acadêmicos universitários ou graduandos de Naturologia. Os resultados demonstraram que a maioria destes profissionais $(82,4 \%)$ está atuando diretamente com a Naturologia. O setor privado é o que possui o maior número de Naturólogos (94,7\%), sendo os consultórios o local de maior atuação, conforme $51,8 \%$ dos pesquisados relataram. Entre os pesquisados, $77 \%$ declararam possuir algum tipo de formação profissional além da graduação em Naturologia, tendo destaque a especialização lato-sensu, referida por $72 \%$ dos participantes. Ainda segundo a pesquisa, 7,1\% possuem mestrado e 1,6\%, doutorado, enquanto nenhum dos participantes havia concluído o pós-doutorado.

Após 2 anos da pesquisa realizada por Conceição e Rodrigues, foi realizada em Março de 2013 uma Pesquisa de Mapeamento dos Naturólogos no Brasil, com o objetivo de descrever características demográficas, sociais e profissionais do profissional. A amostra da pesquisa foi constituída por 457 participantes, sendo eles graduados ou graduandos em Naturologia. Observa-se também que dos 457 participantes, 329 (72\%) são Naturólogos já formados e os demais 128 (28\%) estarão formados de 2013 até 2017. Foi considerado 5\% de erro amostral nesta pesquisa. Observou-se uma maior concentração de Naturólogos em São Paulo (56,6\%) e Santa Catarina $(28,5 \%)$. Com relação a especialização, a maior pre- valência é de especialização em acupuntura (20,4\%), 3,9\% fazem ou fizeram Mestrado e 1,3\% fazem ou fizeram Doutorado. De acordo com a pesquisa, 73,5\% dos formados atuam na área de formação em Naturologia, observa-se também que a grande maioria destes Naturólogos (76,8\%) atuam de forma autônoma no mercado. Os locais de atuação que mais se destacaram foram os de atendimento em Consultórios (33,3\%), Atendimentos Domiciliares (18\%), Clínicas Multidisciplinares (10,8\%) ${ }^{26}$.

\section{ACEITAÇÃO, CONHECIMENTO, SATISFACC̃̃O E RESOLUTIVIDADE DA NATUROLOGIA}

Em um estudo sobre avaliação em saúde relacionado a Naturologia, que teve como objetivo identificar a satisfação dos usuários, a resolutividade dos atendimentos, o conhecimento e a aceitação das Práticas Integrativas e Complementares prestadas pela Seção de Naturologia Aplicada na Assembléia Legistativa do Estado de Santa Catarina. Os resultados demonstraram que a maioria $(67,1 \%)$ conhecia as Práticas Integrativas e Complementares, mas grande parte (52,5\%) não fazia uso; entre os usuários $(73,8 \%)$ conhecia a profissão do naturólogo, antes de serem atendidos no local. A maioria dos usuários $(83,8 \%)$ considera o grau de satisfação pelo atendimento como "excelente"; $(85,3 \%)$ relataram que o atendimento com a Naturologia melhorou sua saúde; $(84,9 \%)$ que o seu problema de saúde foi resolvido com o atendimento. A maioria absoluta (97,4\%) acredita que a Seção de Naturologia tem resolutividade no atendimento de seu usuário, $(95,0 \%)$ acreditam no efeito das Práticas Integrativas e Complementares e $(97,4 \%)$ indicariam o tratamento com a Naturologia para outras pessoas ${ }^{27}$.

\section{ÓRGÃOS DE REPRESENTAÇÃO DOS NATURÓLOGOS}

Os profissionais formados e os estudantes de $\mathrm{Na}$ turologia hoje têm suporte das associações:

»ABRANA - Associação Brasileira de Naturologia, fundada em 27 de abril de 2004.

»APANAT - Associação Paulista de Naturologia, fundada em 08 de maio de 2007. 
Entre as diversas realizações, destacam-se a realização de cursos e palestras; contratação de convênios e parcerias para os associados; mobilização para obtenção do CCM e do CBO; obtenção do Cadastro de Contribuinte Mobiliário - CCM, para o Naturólogo em São Paulo, com a ajuda do vereador Celso Jatene (o CCM Naturólogo para cadastramento de pessoa física é 04596; e o CCM Naturólogo para cadastramento de pessoa jurídica é 04588); realização e organização anual do Congresso Brasileiro de Naturologia (ANEXO VII), sendo o mais recente o $\mathrm{V}$ Congresso, em outubro de 2012 (ANEXO VIII); promoção e participação do Fórum Conceitual e Jornada do Símbolo da Naturologia; criação da Revista Natural em Dia, ISSN 2179-9598 em 2010, com 2 edições impressas (5mil exemplares cada) e em formato virtual no site da ABRANA; realização do $1^{\circ}$ Encontro dos Naturólogos do Sul do Brasil, em maio de 2011; entrevistas na Radio e TV e Entrega do Projeto de Lei para regulamentação da profissão de Naturologia.

Associação Brasileira de Naturologia - ABRANA www.abrana.org.br

abrana.naturologia@gmail.com

$w w w$.facebook.com/abranaoficial? $f r e f=t s$

Associação Paulista de Naturologia - APANAT www.apanat.org.br/>

apanat@apan-at.org.br

www.facebook.com/apanat.associacaopaulistanatur ologia?fref $=$ ts

\section{EVENTOS E PUBLICAÇÕES CIENTÍFICAS}

A Naturologia tem publicados artigos, trabalhos, dissertações, teses, manuscritos em periódicos e livros que dão suporte científico à atuação do Naturólogo. Segue algumas publicações importantes da área:

\section{Revistas Científicas}

- Cadernos de Naturologia e Terapias Complementares - v. 1, n. 1 (2012). Disponível em: www.portaldeperiodicos.unisul.br/index.php/CNTC

- Cadernos Acadêmicos - v. 3, n. 2 (2011). Disponível em:

www.portaldeperiodicos.unisul.br/index.php/

Cadernos_Academicos/issue/view/66

- Cadernos Acadêmicos - v.3, n. 1 (2011). Disponível em: www.portaldeperiodicos.unisul.br/index.php/

Cadernos_Academicos/issue/view/62

\section{Publicações Científicas}

- Elaine de Azevedo \& Maria Cecília Focesi Pelicioni - Práticas Integrativas e Complementares de desafio para a educação. Disponível em: www.scielo.br/scielo.php?script $=$ sci_ arttext\&pid=S1981-77462011000300002\&lng=pt \&nrm=iso\&tlng=pt

- Fernando Hellmann \& Marta Inez Machado VerdiII - Temas e referenciais de análise em Bioética no ensino da graduação em naturologia no Brasil à luz da bioética social. Disponível em:

www.scielo.br/scielo.php?pid=S14143283201200 0300012\&script=sci_arttext

- Paula Cristina Ischkanian \& Maria Cecília Focesi Pelicioni - Desafios das práticas integrativas e complementares no SUS visando a promoção da saúde. Disponível em: http://pepsic.bvsalud.org/ $p d f / r b c d h / v 22 n 2 / p t+16 . p d f$

- Paula Cristina Ischkanian \& Maria Cecília Focesi Pelicioni - Práticas integrativas e complementares para a promoção da saúde. Disponível em: www.teses.usp.br/teses/disponiveis/6/6135/tde13092011-095744/pt-br.php

- Daniel Maurício de Oliveira Rodrigues, Fernando Hellmann \& Nathália Martins Pereira Sanches A Naturologia e a interface com as racionalidades médicas. - Disponível em:

www.google.com.br/url? sa $=$ t\&rct $=j \& q=\& e s r c=s$ \&source $=$ web $\& c d=8 \&$ ved $=0 \mathrm{CHgQFjAH} \& u r l=h$ ttp\%3A\%2F\%2Fwww.portaldeperiodicos.unisul. br\%2Findex.php\%2FCadernos_Academicos\%2 Farticle\%2Fdownload\%2F668\%2F619\&ei=Vo8 RUc7kGJGE8ATp2YCYAw\&usg=AFQjCNHiOs 5m7_Ef423gx88_3fCyWELmMw\&sig2=p14mfm xuropnrEnQMMyKPw

- Fernanda Campos Sousa Almeida, Dorival Pedroso da Silva, Sandra Melo Martins, Flavia Placeres, Amanda Ghiraldelli Giuseppe, Reinaldo Brito e Dias, Maria Ercilia de Araújo - Revisão Sistemática. As terapias naturais: Um convite ao aprendizado e a reflexão. Disponível em: 
www.ufpe.br/ijd/index.php/exemplo/article/ view/246

- Carla Raifra Brandão Rodrigues, Dinorá Regina Pereira Lima \& Marcia Figueiredo - O Papel de educador do Naturólogo no resgate da autoestima na comunidade de Heliópolis. Disponível em: www.cooperativateor.com.br/sms/files/file/PEREIRA\%20Dinora\%20TCC.pdf

- Ana Cláudia Moraes Barros Leite-Mor, Cristiane Spadacio, Nelson Filice de Barros - Práticas tradicionais, integrativas e complementares em saúde no Brasil: Uma metassíntese de estudos sociológicos. Disponível em:www.convencionsalud2012. sld.cu/index.php/convencionsalud/2012/paper/ viewPaper/1529

- Fernando Hellmann \& Leonardo de Couto Meneguzzi - Educação em saúde como mecanismo no fortalecimento da autonomia dos interagentes: Concepção de bacharéis em Naturologia Aplicada. Disponível em: www.google.com.br/\#hl=pt$-\mathrm{BR} \&$ tbo $=\mathrm{d} \&$ sclient $=\mathrm{psy}-\mathrm{ab} \& \mathrm{q}=$ Fernando + Hellm ann\%2BLeonardo+de+Conto++Meneguzzi\&oq= Fernando+Hellmann\%2BLeonardo+de+Conto+ +Meneguzzi\&gs_l=serp.3...28433.63621.1.64116. 10.9.1.0.0.0.288.1448.0j4j3.7.0...0.1...1c.1j2.2.serp. PaVdlfUTzwU\&pbx=1\&bav=on.2,or.r_gc.r_pw.r_ qf. $\& f p=d 8006 \mathrm{c} 214180 \mathrm{bb} 82 \& \mathrm{biw}=1280 \& \mathrm{bih}=656$

- Ana Claudia Moraes Barros Leite-Mor \& Nelson Filice de Barros - Naturologia e a emergência de novas perspectivas na saúde. Disponível em: $w w w$. portaldeperiodicos.unisul.br/index.php/Cadernos_ Academicos/article/view/715\#.URGn-R072Ag

- Adriana Elias Magno da Silva - Naturologia: prática médica, saberes e complexidade. Disponível em: www.apanat.org.br/_upload/repository/Naturologia_Adriana\%20Magno.pdf

- Caio Fábio Schlechta Portella, Édison Alves Pereira, Bruna Rei Freitas, Paola Favero, Matteo Napolitano \& Paola Pedullo - A atuação do Naturologo em equipe multiprofissional dentro do programa estadual de saúde integral do adolescente - PEPISA. Disponível em: www.apanat.org.br/_upload/repository/anais11.pdf

\section{Livros}

- RODRIGUES, Daniel M. O.; HELLMANN, Fernando; DARÉ, Patrícia K.; WEDEKIN, Luana M. Naturologia: diálogo e perspectivas - Palhoça: Editora Unisul, SC, 2012.

- WEDEKIN, Luana M.; HELLMANN, Fernando; DELLAGIUSTINA, Marilene. Naturologia Aplicada: reflexões sobre saúde integral - Tubarão: Ed. Unisul, 2008.

- WEDEKIN, Luana M.; HELLMANN, Fernando. O livro das interagências: estudos de casos em Naturologia. Tubarão: Ed. Unisul, 2008.

Publicações no meio científico da importância das Medicinas Tradicionais (MT), Medicinas Complementares/Alternativas (MAC), Práticas Integrativas e Complementares (PICS) e da Naturologia na Saúde:

- BARROS, N. F. de. A construção da medicina integrativa: um desafio para o campo da saúde. São Paulo: Hucitec, 2008.

- LUZ, M. T.; BARROS, N. F. Racionalidades Médicas e Práticas Integrativas e Complementares em Saúde: estudos teóricos e empíricos. Rio de Janeiro, UERJ, IMS, LAPPIS, 2012.

- BARROS, N. F. de; NUNES, E. D.; Medicina Alternativa e Complementar no Brasil: um conceito e diferentes significados. Cadernos de Saúde Pública. Rio de Janeiro, v. 22(10), p. 2023-2039, Out. 2006.

- BASTOS, F. A. S. Análise da Política de Práticas Integrativas e Complementares no Recife. Dissertação (Mestrado em Saúde Pública) - Centro de Pesquisas Aggeu Magalhães - Fundação Oswaldo Cruz, Recife, 2010.

- BRASIL. Ministério da Saúde. Secretaria de Atenção à Saúde. Departamento de Atenção Básica. Política Nacional de Práticas Integrativas e Complementares no SUS - PNPIC. Brasília: Ministério da Saúde, 2006a.p. 92 (Série B. Textos Básicos de Saúde).

- BRASIL. Ministério da Saúde. Portaria n 971, 3 de maio de 2006. Aprova a Política Nacional de Práticas Integrativas e Complementares -PNPIC no Sistema Único de Saúde. 2006b. 
Acesso em: 22 Jan, 2012. Disponível em:

bvsms.saude.gov.br/bvs/saudelegis/gm/2006/

prt0971_03_05_2006.html

- CARVALHO,A. C. D.; MARTINEZ, E.Z.; MANZINI,

T. Conhecimento, crença e uso da medicina alternativa e complementar por fonoaudiólogos. Revista Brasileira de Epidemiologia, v. 11(2), p. 304-14, 2008.

- DE SIMONI, C.; BENEVIDES, I.; BARROS, N. F. As práticas Integrativas e Complementares no SUS: realidade e desafios após dois anos de publicação da PNPIC. Revista Brasileira Saúde da Família. Ano IX. Edição Especial, Maio, p. 70-76, 2008.

- FONTANELLA, F.; SPECK, F. P.; PIOVEZAN, A. P.; KULKAMP, I. C. Conhecimento, acesso e aceitação das práticas integrativas e complementares em saúde por uma comunidade usuária do Sistema Único de Saúde na cidade de Tubarão/SC. Arquivos Catarinenses de Medicina, v. 36, n. 2, 2007.

- KÜLKAMP, I. C.; BURIN, G. D.; SOUZA, M. H. M. de; SILVA, P. da; PIOVEZAN, A. P. Aceitação de Práticas Não-Convencionais em Saúde por Estudantes de Medicina da Universidade do Sul de Santa Catarina. Revista Brasileira de Educação Médica. Rio de Janeiro, v. 29, nº 1, 2007.

- LUZ, M. T. Racionalidades médicas e terapêuticas alternativas. Rio de Janeiro: IMS/UERJ, 1996. p. 23. [Série Estudos em Saúde Coletiva, 62]

\section{- LUZ, M. T. Cultura Contemporânea e Medicinas} Alternativas: Novos paradigmas em saúde no fim do século XX. PHYSIS: Revista Saúde Coletiva. Rio de Janeiro, 15 (Suplemento), p.145-176, 2005.

- NOGUEIRA, M. I. Racionalidades médicas e formação em saúde: uma caminha para a integralidade. In: Por uma sociedade cuidadora. PINHEIRO, R.; SILVA JR., A. G. S. (Org.). Rio de Janeiro: CEPESC: IMS/UERJ, 2010.

- PINHEIROS, R.; MATTOS, R.A. Construção da integralidade: cotidiano, saberes e práticas em saúde. 4. ed. Rio de Janeiro: IMS/UERJ - CEPESC.

- TESSER, C. D.; BARROS, N. F. de. Medicalização social e medicina alternativa e complementar: pluralização terapêutica do Sistema Único de Saúde. Revista de Saúde Pública. São Paulo, v. 42, n. 5, p. 914-920, out. 2008.

\section{- WORLD HEALTH ORGANIZATION. Estrategia} de la OMS sobre medicina tradicional. 2002-2005. Genebra: WHO. 2002.

- WORLD HEALTH ORGANIZATION. Traditional medicine: definitions. 2012. Genebra. 2012.

\section{Tese de doutorado}

- Adriana Elias Magno da Silva - Naturologia: um diálogo entre saberes. Tese.Doutorado em Ciências Sociais. PUC-SP. 2012.

Disponível em: www.sapientia.pucsp.br/tde_busca/arquivo.php?codArquivo $=15262$

\section{EVENTOS}

Anualmente é realizado o Congresso Brasileiro de Naturologia, que está na sua VI edição. Todo evento contém comissão cientifica e apresentação de trabalhos científicos.

Dentre as temáticas já discutidas, estão:

\section{CONBRANATU - 2008/SP}

Tema: A Naturologia seus pilares, práticas e terapias. Objetivo:

- Divulgação da Naturologia

Disponível em:

www.apanat.org.br/noticias/eventos/i-congresso-brasileiro-de-naturologia-2008/

\section{CONBRANATU - 2009/SC}

Tema: O perfil do Naturólogo.

Objetivo:

- Incentivo e a divulgação de estudos e pesquisas na área das Práticas Integrativas e Complementares.

Disponível em:

www.apanat.org.br/_upload/repository/anais.pdf www.apanat.org.br/noticias/eventos/anais-do-ii-congresso-brasileiro-de-naturologia-2009/

\section{CONBRANATU - 2010/PR}

Tema: A Naturologia e a Medicina Integrada Objetivo:

- A união e troca de experiências entre profissionais da saúde que utilizam as terapias naturais para promover a saúde. 
- Realizado em Curitiba com o IX Encontro Interna-

cional de Medicina Integrada; e com o $1^{\circ}$ Simpósio

da União das Entidades de Medicina Integrada.

Disponível em:

www.apanat.org.br/noticias/eventos/iii-congresso-

-brasileiro-de-naturologia-2010/

\section{CONBRANATU - 2011/SP}

Tema: Naturologia e Saúde Pública e Coletiva

Objetivos:

- Políticas de Promoção de saúde, PNPIC e Atenção Básica;

- Racionalidades médicas, Inter/Transdisciplinaridade;

- Experiência de Saúde e doença, Humanização e

Interagência;

- Terapias Naturais e Integrativas Aplicadas no SUS.

Disponível em:

www.apanat.org.br/_upload/repository/Cursoseeventos/ANAIS\%20IV\%20CONBRANATU.pdf

www.apanat.org.br/noticias/eventos/anais-do-iv-congresso-brasileiro-de-naturologia-2011/

\section{CONBRANATU - 2012/SC}

Tema: A Naturologia e a Prática Clínica

Objetivos:

- Evidências Científicas em Naturologia e nas Prá-

ticas Integrativas e Complementares;

- Mercado de Trabalho do Naturólogo;

- Experiências de Naturólogos nos diversos cam-

pos de atuação.

Disponível em:

www.apanat.org.br/_upload/repository/anais12.pdf www.apanat.org.br/noticias/eventos/anais-do-v-congresso-brasileiro-de-naturologia-2012/

Junto ao congresso, também são realizados os Fóruns Conceituais de Naturologia. Destinam-se a estimular e aprofundar as reflexões sobre os princípios e diretrizes da Naturologia, a fim de contribuir para a construção de suas bases epistemológicas e de sua práxis. A Jornada do Simbolismo da Naturologia, também realizada durante o último Congresso, apresentou algumas reflexões sobre imagens que poderiam representar a Naturologia.

Disponível em:

www.apanat.org.br/_upload/repository/anais12.pdf

\section{NOTAS EXPLICATIVAS:}

${ }^{\text {I }}$ Para saber mais sobre o Projeto de Lei, acesse o site: www2.camara.leg.br/camaranoticias/noticias/ trabalho-e-previdencia/69414-profissao-de-naturologo-pode-ser-regulamentada.html.http://www2. camara.leg.br/camaranoticias/noticias/trabalho-e-previdencia/69414-profissao-de-naturologo-pode-ser-regulamentada.html.

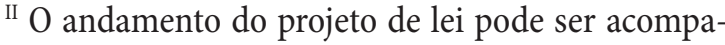
nhado pelo endereço eletrônico em: www.camara. gov.br/proposicoesWeb/fichadetramitacao?idPropos $i c a o=543332 h t t p: / / w w w . c a m a r a . g o v . b r / p r o p o s i c o-$ esWeb/fichadetramitacao?idProposicao $=543332$.

III A Naturologia embasa-se em um conjunto de diferentes sistemas terapêuticos pelo entendimento de que a complexidade do processo de vida-saúde-doença não pode ser compreendida por uma única racionalidade. Para isso a Naturologia não busca a princípio a especialização, mas uma formação ampliada, bem como novas formas de produção do conhecimento, como a complexidade e a transdisciplinaridade.

${ }^{\text {IV }} \mathrm{O}$ que caracteriza os sistemas terapêuticos de base da Naturologia - a saber: as Medicinas Tradicionais Chinesa, Ayurveda e Xamânica e a Antroposofia. A perspectiva vitalista, ou seja, a proposição de que o processo terapêutico se dá pela reorganização e restabelecimento do equilíbrio vital do organismo. Neste sentido, os conhecimentos de base da Naturologia são preponderantemente formas de prevenção de agravos e doenças e de promoção da saúde.

v Os sistemas terapêuticos vitalistas caracterizam-se também por uma não separação entre processos físico-biológicos, psíquicos, mentais, espirituais, ambientais e sociais. Portanto, sua visão e entendimento do processo de vida-saúde-doença são necessariamente multidimensionais.

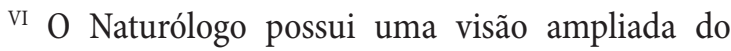
processo saúde-doença, considerando o indivíduo tratado como interagente, e não paciente, pois este participa ativamente do processo de cura. A relação de interagência preconiza o cuidado humanizado, a escuta acolhedora, o desenvolvimento do vínculo terapêutico e a autonomia do sujeito.

VII Essas outras racionalidades terapêuticas referem-se às medicinas tradicionais (Medicina Tradicional Chinesa e Ayurveda) e demais racionalidades (Antroposofia) que não podem ser classificadas como ciência natural ou ciência humana. 


\section{CONFLITOS DE INTERESSE}

Declararam não haver

\section{FONTES DE FINANCIAMENTO}

nenhuma

\section{AUTORIA}

Os autores S.H.F. Sabbag, F. Placeres, B.M.R. Nogueira e A.L.L De Callis participaram da concepção, delineamento e redação do texto. A.C.M.B Leite-Mor, C.F.S. Portella e R.L. Antônio participaram da concepção, redação do texto e definição de conceitos. D.M.O. Rodrigues trabalhou na análise, interpretação dos dados, revisão crítica e redação do manuscrito.

\section{AGRADECIMENTOS:}

Os autores agradecem aos naturólogos Amanda G. Guiseppe, Ana Elise Silotto, Bruna Rei, Kalil Mondadori, Neila Lopes e Suely Ramos Bello e também aos acadêmicos Daniele Leão Freitas, Carina Ceratti e Mayara Aparecida Passos que participam do grupo de apoio ao projeto de lei de regulamentação do naturólogo

\section{REFERÊNCIAS}

1 - BRASIL. Ministério da Saúde. Sistema Único de Saúde (SUS): princípios e conquistas. Brasília: Ministério da Saúde. 2000.

2 - PAIM P, TRAVASSOS C, ALMEIDA C, BAHIA L, MACINKO J. O sistema de saúde brasileiro: história, avanços e desafios. The lancet. 2011. Maio. 11-31.

3 - RODRIGUES DMO, HELLMANN F, SANCHES NMP. A naturologia e a interface com as racionalidades médicas. Cadernos Acadêmicos. 3(1) 24-36.

4 - BRASIL. Relatório Final da XI Conferência Nacional de Saúde. Brasília: Ministério da Saúde, 2000.

5 - BRASIL. Política Nacional de Práticas Integrativas e Complementares no SUS; Ministério da Saúde, 2006: Http://bvsms. saude.gov.br/bvs/publicacoes/pnpic.pdf

6 - SILVA AEM. Naturologia: prática médica, saberes e complexidade. 2008. In: Anais da Jornadas de Investigacion em Antropología Social. 2008: Buenos Aires.

7 - Associação Paulista de Naturologia. Visão, missão e valores. São Paulo: APANAT. 2013

8 - Associação Brasileira de Naturologia. Estatuto. Florianópolis. 2013

9 - EVANGELISTA BCW. O profissional naturólogo inserido no Sistema Único de Saúde: levantamento atualizado no âmbito nacional. Goiânia. 2012.

10 - JATENE C. O dia do profissional em terapias naturais e do naturólogo, e da outras providências. Projeto de Lei 503/04. São Paulo.http://www.celsojatene.com.br/projetos_interna.php?id=126

11 - ABRANA. Dia do naturólogo em Florianópolis - SC. http://www. abrana.org.br/agora-e-oficial-dia-do-naturologo-em-florianopolis-sc/

12 - RODRIGUES DMO, HELLMANN F, SANCHES NMP. Para pensar a Naturologia: diferenças conceituais nos campos dos cuidados não convencionais em saúde. In: RODRIGUES DMO. et al. (Org.). Naturologia: diálogos e perspectivas. Tubarão: Unisul; 2012.p. 71-84.

13 - RODRIGUES DMO. O naturólogo: as Práticas Integrativas e Complementares e a Qualidade de Vida. In: MARTINS RS, HAGEN SA. (Org.). Ame suas rugas: aproveite o momento. Blumenau: Odorizzi; 2007. p. 43-55.

14 - SILVA AEM. Naturologia: um diálogo entre saberes [tese de doutorado]. São Paulo: Pontifícia Universidade Católica de São Paulo (PUC-SP); 2012. Disponível em: <http://www.sapientia. pucsp.br/tde_busca/arquivo.php? $\operatorname{cod}$ Arquivo=15262>

15- RODRIGUES DMO, HELLMANN F, SANCHES NMP. Apresentação. In: Anais V Congresso brasileiro de naturologia. III Fórum conceitual de Naturologia; 2012 out; Florianópolis(Br): ABRANA; 2012.p. 9.
16 - CARMO RK, COBO GA, HELLMANN F. A relação de interagência sob a perspectiva da abordagem centrada na pessoa. Cadernos de Naturologia e Terapias Complementares. 2012. 1(1).30-41.

17 - LYRA CS, NAKAI LS, MARQUES AP. Eficácia da aromaterapia na redução de níveis de estresse e ansiedade em alunos de graduação da área da saúde: estudo preliminar. Fisioterapia e Pesquisa. 2010. 17(1): 13-17.

18 - GNATTA JR, DORNELLAS EV, SILVA MJP. O uso da aromaterapia no alívo da ansiedade. Acta Paulista de Enfermagem. 2011 24(2): 257-263.

19 - DESCRITORES EM CIÊNCIAS DA SAÚDE. BIREME. Biblioteca Virtual em Saúde. 2013.

20 - RADELJAK S, ZARKOVIĆ-PALIJAN T, KOVACEVIĆ D, KOVAC $M$. Chromotherapy in the regulation of neurohormonal balance in human brain - complementary application in modern psychiatric treatment. 2008. Coll Antropol 10(32): 185-188.

21 - IRONSON G, FIELD T, SCAFIDI F, HASHIMOTO M, KUMAR M, KUMAR A, PRICE A, et al. Massage therapy is associated with enhancement of the immune system's cytotoxic capacity. International Journal of Neuroscience. 1996. 84(1-4): 205-217.

22 - SLIZ D, SMITH A, WIEBKING C, NORTHOFF G, HAYLEY S. Neural correlates of a single-session massage treatment. Brain Imaging and Behavior. 2012. 6(1): 77-87.

23 - MIERNIK M, WIECKIEWICZ M, PARADOWSKA A, WIECKIEWICZ W. Massage therapy in myofascial TMD pain management. Advances in Clinical and Experimental Medicine. 2012. 21(5): 681-685.

24 - KOZASA EH, SATO JR, LACERDA SS, BARREIROS MA, RADVANY J, RUSSELL TA, SANCHES LG, et al. Meditation training increases brain efficiency in an attention task. Neuroimage. 2012. 59(1): 745-749.

25 - CONCEIÇÃO SS, RODRIGUES DMO. A situação socioeconômica e profissional dos naturólogos no Brasil,. Cadernos Acadêmicos. 2011. Jan-Jul 3(1): 103-120.

26 - FREITAS DL, RODRIGUES DMO, CERRATI C, PLACERES F, SABBAG S. A situação profissional dos naturólogos no Brasil. ABRANA e APANAT. 2013.

27- LOSSO LN, RODRIGUES DMO. Avaliação da assistência à saúde: conhecimento, aceitação, satisfação e resolutividade no atendimento ao usuário da seção de Naturologia Aplicada da Assembleia Legislativa do Estado de Santa atarina - ALESC. Trabalho de conclusão de curso. Universidade do Sul de Santa Catarina. 2012. 


\section{ANEXO I \\ (APROVAÇÃO DO MEC UNISUL)}

(Código) Grau:

Modalidade:

Data de início do funcionamento do curso:

Carga horária mínima:

Coordenador:

Disponível em:

$<$ http://emec.mec.gov.br/emec/consulta-cadastro/detalhamento/d96957f455f6405d14c6542552b0f6eb/NDk0

/9f1aa921d96ca1df24a34474cc171f61/MzkzOA==>

DETALHES DA IES

(Código) Nome da IES:

(494) UNIVERSIDADE DO SUL DE SANTA CATARINA - UNISUL

\section{DETALHES DO CURSO}

Link site sobre naturologia:

<http://www.unisul.br/wps/portal/home/ensino/graduacao/naturologia\#?unidade=11>

Facebook: https://www.facebook.com/naturologiaunisul?fref=ts
(19474) Bacharelado em NATUROLOGIA APLICADA

Educação Presencial

02/03/1998 Periodicidade (Integralização) Semestral (9.0)

3390 horas Vagas Autorizadas:

120

FERNANDO HELLMANN 


\section{ANEXO II \\ (APROVAÇÃO DO MEC UAM)}

(Código) Grau:

Modalidade:

Data de início do funcionamento do curso:

Carga horária mínima:

Coordenador:

Ato Regulatório:

Reconhecimento de

Curso

Tipo de documento:

Portaria SESu

Data do Documento:

No. Parecer / Despacho: 138/2007 SESu

Ato Regulatório:

Autorização

Prazo de validade:

No. Documento:

161 de $16 / 02 / 2007^{*}$

Data de Publicação:

$21 / 02 / 2007$

Data do Despacho:

$$
\text { (Integralização) }
$$

Vagas Autorizadas:

Vinculado ao Ciclo Avaliativo

ANDRE LUIZ RIBEIRO

Presencial

Prazo de validade:

Semestral (9.0)

120

Art. 35 Decreto 5.773/06

(Redação dada pelo Art. 2

Decreto 6.303/07)

Tipo de documento:

Resolução CONSUN No. Documento:

$003 / 01$

Data do Documento:

Data de Publicação:

$29 / 06 / 2001$

No. Parecer / Despacho:

Data do Despacho:

Disponível em:

<http://emec.mec.gov.br/emec/consulta-cadastro/detalhamento/d96957f455f6405d14c6542552b0f6eb/NDY 2/9f1aa921d96caldf24a34474cc171f61/MzkzNw>

Link site sobre naturologia:

$<$ http://portal.anhembi.br/publique/Estude-aqui/Graduacao/Cursos/Graduacao/Naturologia-153.html>

Facebook: $h t t p s: / / w w w . f a c e b o o k . c o m / n a t u r o l o g i a . a n h e m b i m o r u m b i ? f r e f=t s$ 


\section{ANEXO III \\ (CARTA DE INTENÇÃO UNIVERSIDADE DO PARANÁ)}

\section{$1{ }^{\circ}$ FÓRUM NACIONAL DE RACIONALIDADES MÉDICAS E PRÁTICAS INTEGRATIVAS E COMPLEMENTARES EM SAÚDE - INTERCÂMBIO SOLIDÁRIO DE SABERES E PRÁTICAS}

25 a 28 de abril de 2012 - Universidade Federal Fluminense - Campus Gragoatá - Niterói - RJ

Programação - Comunicação Oral

26/04/2012 - 14:00 - 15:00

Formação para Serviços em RM e PICS-Ensino técnico, de graduação, pós-graduação e cursos livres em RM e PICS de relevância para a área da saúde (subeixo $B$ )

PROPOSTA DE GRADUAÇÃO EM NATUROLOGIA NA UNIVERSIDADE FEDERAL DO PARANÁ (UFPR): NOVAS PERSPECTIVAS PARA FORMAÇÃO EM RACIONALIDADES MÉDICAS (RM) E PRÁTICAS INTEGRATIVAS E COMPLEMENTARES EM SAÚDE (PICS)

MARCOS CLAUDIO SIGNORELLI - UFPR, DANIEL CANAVESE - UFPR, CLÓVIS WANZINACK - UFPR, IONE MARIA ASCIDAMINI - UFPR, NADIA TEREZINHA COVOLAN - UFPR, NEILOR KLEINÜBING UFPR, SUZANA CINI FREITAS NICOLODI - UFPR

Este trabalho objetiva a descrição da proposta de criação da Graduação em Naturologia pela UFPR, refletindo sobre algumas das potencialidades de tal empreendimento. A UFPR, buscando consolidar-se como um agente de desenvolvimento regional sustentável, implantou em 2005 a UFPR Litoral em Matinhos, litoral do Paraná. A UFPR Litoral está numa região riquíssima em recursos naturais, mas, ao mesmo tempo, as comunidades que vivem em seu entorno enfrentam graves problemas sociais, econômicos e de saúde. Nesse sentido, partindo da premissa de que só ocorre o desenvolvimento sustentável quando seres humanos e meio ambiente são capazes de conviver em equilíbrio, o curso de Naturologia objetiva o estabelecimento de uma relação harmoniosa entre pessoas e a natureza. Atualmente, a saúde vive um momento de transição paradigmática. $\mathrm{O}$ modelo hegemônico de produção de saúde, influenciado pela biomedicina, centrado em tratamento de doenças, medicalização, modelos hospitalocêntricos, tecnologias duras, e especialismo, não dá conta de promover integralmente a saúde. Tal modelo engendra um modo de pensar a saúde altamente desigual, que exclui pessoas, em especial aquelas com menor poder aquisitivo para "consumi-lo", assim como as que habitam fora dos grandes centros urbanos. Por outro lado, outros modos de conceber a saúde vêm emergindo, sendo assinaladas distintas racionalidades, tais como os modelos com foco em questões biopsicossociais, bioenergéticas, modos de concepção de saúde autóctones, com resgate de saberes populares e tradicionais, em abordagens mais próximas do que vem sendo desenhado pelo SUS como "integralidade em saúde". Desse modo, a formação em Naturologia vem ao encontro destas outras racionalidades possíveis de conceber a saúde, deslocando o foco da centralidade nas doenças, para a promoção da saúde, com resgate das práticas naturais e dos saberes tradicionais. A graduação em Naturologia permitirá à/ao estudante vivências teórico-práticas acerca de recursos e técnicas naturais que possam ser utilizadas na promoção da saúde, bem-estar e equilíbrio, visando a integração do ser humano consigo mesmo, com suas coletividades e com a natureza. $\mathrm{O}$ curso também permitirá o fomento de ações ligadas à "Política Nacional de Práticas Integrativas e Complementares", objetivando a inserção das PICS no âmbito do SUS, universalizando o acesso por meio de estratégias individualizadas e/ou coletivas, nos diferentes níveis de atenção à saúde. Desde 2008, o coletivo de docentes da UFPR Litoral, que acumula o êxito na implantação de uma graduação em Saúde Coletiva, organiza a proposta da graduação em Naturologia. Para tanto, realiza estudos técnicos do mundo do trabalho, em propostas de cursos já existentes, além da elaboração do projeto do curso. $O$ grupo pretende materializar a referida graduação a partir de 2012, aproveitando a fase 2 do Programa de Reestruturação e Expansão das Universidades Federais (REUNI), almejando, portanto, ampliar o acesso às distintas RM e PICS.

Disponível em:

$<$ http://www.forumrmpics2012.com.br/programacao/exibe_trabalho.php?id_trabalho=18875\&id_ atividade $=2729 \&$ tipo $=>$ 


\section{ANEXO IV \\ (EDITAIS DE CONCURSOS PARA NATUROLOGIA)}

Tabela 1 Vagas ofertadas em concursos públicos para naturólogos

\begin{tabular}{|c|c|c|c|c|}
\hline ANO & MUNICÍPIO & ESTADO & $\begin{array}{c}\text { VAGAS POR } \\
\text { MUNICÍPIO }\end{array}$ & IDENTIFICAÇ̃̃O \\
\hline 2007 & São Joaquim & Santa Catarina & 2 & ANEXO IV a \\
\hline 2009 & Laguna & Santa Catarina & 1 & ANEXO IV b \\
\hline 2009 & Registro & São Paulo & 1 & ANEXO IV c \\
\hline 2011 & Ermo & Santa Catarina & 1 & ANEXO IV d \\
\hline 2011 & Vilhena & Rondônia & 1 & ANEXO IV e \\
\hline 2012 & Macaé & Rio de Janeiro & 1 & ANEXO IV f \\
\hline 2012 & Santa Gertrudes & São Paulo & 1 & ANEXO IV g \\
\hline
\end{tabular}

FONTE: EVANGELISTA, 2012.

\section{ANEXO IV A}

Edital de Concurso Público, município de São Joaquim, estado de Santa Catarina.

Disponível em: <http://www.pciconcursos.com.br/concurso/prefeitura-de-sao-joaquim-sc-112-vagas>

\section{ANEXO IV B}

Edital de Concurso Público, município de Laguna, estado de Santa Catarina

Disponível em: <http://www.pciconcursos.com.br/concurso/prefeitura-de-laguna-sc-85-vagas $>$

\section{ANEXO IV C}

Edital de Concurso Público, município de Registro, estado de São Paulo, o link deste edital não está mais disponível, segue descrição abaixo.

Edital Município de Registro - SP

Ainda havendo igualdade de pontos, o desempate ocorrerá na nomeação do candidato, por sorteio.

\section{CAPÍTULO VII - DA CONTRATAÇÃO}

Os candidatos classificados serão contratados pela Associação de Proteção à Maternidade e Infância de Registro - APAMIR, nos termos do Convênio com a Prefeitura Municipal de Registro através da Lei 517/2005 de 31/03/2005, sob a égide da Consolidação das Leis do Trabalho - CLT.

O candidato classificado na vaga terá seu contrato estabelecido por tempo indeterminado.

O candidato que não atender a convocação para contratação será desclassificado do certame.

O não comparecimento, por qualquer motivo, para a contratação na data determinada pele Departamento Municipal de Saúde, acarretará a perda do direito a vaga, sendo convocado o candidato subsequente.

A contratação dos candidatos obedecerá à ordem da classificação, devendo iniciar-se pela lista de pontuação geral. É facultativo ao Departamento Municipal de Saúde de Registro, exigir dos candidatos convocados, além da documentação prevista na C.L.T., outros documentos que julgar necessários. 


\section{CAPÍTULO VIII - DAS DISPOSIÇÕES FINAIS}

A homologação do Processo Seletivo será feita pelo Departamento Municipal de Saúde de Registro.

O prazo de validade do Processo Seletivo será de 1 (um) ano, contados da data de sua homologação, podendo ser prorrogado por igual período, a critério do Departamento Municipal de Saúde de Registro.

A aprovação e a classificação geram para o candidato apenas a expectativa de direito à contratação, reservando-se ao Departamento Municipal de Saúde o direito de proceder às contratações, em número que atenda as necessidades de serviço, de acordo com a disponibilidade orçamentária e as vagas existentes.

Os casos omissos serão resolvidos pelo Departamento Municipal de Saúde de Registro.

\section{ANEXO I}

\section{CONHECIMENTOS ESPECÍFICOS}

Fundamentos de Saúde do Trabalhador e da Medicina Chinesa; Relações Saúde - Trabalho; Vigilância em Saúde dos Trabalhadores; Doença do Sistema

Osteomuscular e do Tecido Conjuntivo Relacionadas ao Trabalho; e Portaria n ${ }^{\circ}$ 971, de 3 de maio de 2006/MS.

\section{BIBLIOGRAFIA SUGERIDA}

Doenças Relacionadas ao Trabalho - Manual de Procedimentos para os Serviços de Saúde. Ministério da Saúde. Brasília, 2001.

Portaria $n^{\circ} 2.437 / G M$ de 7 de dezembro de 2005. - Dispõe sobre a ampliação e o fortalecimento da Rede Nacional de Atenção Integral à Saúde do Trabalhador - Renast no Sistema Único de Saúde - SUS e dá outras providências. Para Saber das Coisas Falando da Política Nacional de Saúde do Trabalhador e das Doenças Relacionadas ao Trabalho. Cartilha e Guia de fontes para Radialistas. Ministério da Saúde. São Paulo, setembro de 2006.

Portaria 971, de 3 de maio de 2006/MS

Os Fundamentos da Medicina Chinesa - Um texto Abrangente para Acupunturistas e Fisioterapeutas. Giovanni Maciocia. Ed. ROCA.

\section{ANEXO IV D}

Edital de Concurso Público, município de Ermo, estado de Santa Catarina.

Disponível em: <http://www.pciconcursos.com.br/noticias/prefeitura-de-ermo-sc-oferece-29-vagas-para-nivel-superior-e-alfabetizado $>$

\section{ANEXO IV E}

Edital de Concurso Público, município de Vilhena, estado de Rondônia.

Disponível em: <http://www.resultadoconcursos.net/concurso-prefeitura-de-vilhena-ro-2011-589-vagas/>

\section{ANEXO IV F}

Edital de Concurso Público, município de Macaé, estado de Rio de Janeiro.

Disponível em: <http://pt.scribd.com/doc/102382200/Edital-2>

\section{ANEXO IV G}

Edital de Concurso Público, município de Santa Gertrudes, estado de São Paulo.

Disponível em: <http://concursos.org/sp/santa-gertrudes/concurso-santa-gertrudes-2012-prefeitura/attachment/edital-santa-gertrudes-001-2012> 


\section{ANEXO V \\ NATUROLOGIA NO CENTRO DE REFERÊNCIA EM SAÚDE \\ DO TRABALHADOR DE POÇOS DE CALDAS - MG}

As atividades de Naturologia iniciaram em fevereiro de 2011 com a proposta de agregar valores e complementar os atendimentos clínicos realizados aos trabalhadores de Poços de Caldas e região, utilizando o PIC.

A jornada de trabalho realizada é de segunda a sexta feira, com carga horária de 4 horas diárias, cada atendimento tem duração de 1 hora, sendo feito em cada pessoa um conjunto de 10 sessões. Os indivíduos vêm encaminhados pelos outros profissionais da equipe, como médicos, fisioterapeuta, psicólogo, fonoaudióloga, já com um diagnóstico ou hipótese diagnóstica definidos para serem tratados.

Nos atendimentos são executados procedimentos de massoterapia, cromoterapia/cromopuntura, auriculoterapia, reflexologia, técnicas corporativas, indicações de plantas medicinais, terapia floral e aromaterapia, além de solicitar aos médicos que encaminhem os pacientes para o serviço de termalismo existente na cidade nos Balneários Thermas Antônio Carlos e Dr. Mário Mourão.

Nesses dois anos em que se implantou o serviço de Naturologia, foram assistidas 123 pessoas, realizadas 876 sessões individuais, com um total de 1309 procedimentos executados dentre as terapias listadas acima, tendo maior destaque a auriculoterapia $(n=450)$ e a cromopuntura $(n=385)$, por estas apresentarem bons resultados no tratamento dos principais acometimentos da população, como LER/DORT, distúrbios osteo-mio-articulares e queixas emocionais.

A aceitação da população em relação às PIC é satisfatória no primeiro ano, 55\% das pessoas tratadas executaram 7 ou mais sessões, subindo, no segundo ano, para 61\%, uma vez consideradas as condições em que os trabalhadores se encontram, já que parte deles tem problemas para conciliar o tratamento e a jornada trabalhista seja pela indisponibilidade da empresa em liberá-lo ou pela dificuldade financeira em arcar com gastos com o transporte até o centro de atendimento e depois voltar para o serviço. Outra parte da população frequentou os atendimentos em até 3 sessões (26\%, em 2011, e 16\%, em 2012), compondo esse grupo pessoas que desistiram do tratamento por motivos indefinidos ou por apresentarem mais de duas faltas não justificadas, o que é um critério para a continuidade e o progresso do tratamento.

Na grande maioria as pessoas assistidas realizam as sessões e relatam melhoras significativas. Todos estes se abrem para a experimentação de novas possibilidades e saem satisfeitos com os resultados obtidos, com o atendimento prestado, com os resultados das PIC e o grau de atenção dado a eles. Procura-se na relação naturólogo/interagente a humanização do cuidado, com o ouvir e o modo de lidar com a pessoa de forma individual, compreendendo a integralidade do sujeito.

Relato de experiência: BELCHIOR, Gustavo Moreira. 


\section{ANEXO VI \\ HOSPITAL DAS CLÍNICAS, HOSPITAL PÉROLA BYINGTON E CASA DO ADOLESCENTE DE PINHEIROS - SP}

O Programa Saúde do Adolescente é atualmente reconhecido mundialmente pela OMS como referência à atenção à saúde do adolescente, colaborando no desenvolvimento de políticas públicas em Saúde do Adolescente adotadas no Brasil e no Mundo.

A Naturologia há 6 anos atua como integrante da equipe de atenção ao adolescente, compondo um trabalho em equipe multiprofissional.

Os locais de atuação atualmente são: Hospital das Clinicas/FM-USP - Ambulatório de Ginecologia da Adolescente (desde 2007), Hospital Pérola Byington - ambulatório Terça Rosa (desde 2012 - Ambulatório de Atendimento à Jovem Trabalhadora, com jovens de 16 a 24 anos) e Casa do Adolescente de Pinheiros (desde 2007).

O Naturólogo realiza atendimentos individuais e em grupos (oficinas utilizando diversas técnicas terapêuticas), participa das diversas pesquisas referentes à saúde do adolescente, além da criação e gerenciamento de uma horta medicinal (Casa do Adolescente de Pinheiros), objetivando ensinar e inserir o uso das plantas medicinais no cotidiano dos adolescentes. Neste as plantas medicinais e aromáticas são cuidadas e vivenciadas pelos adolescentes, como um laboratório de educação ambiental e promoção de saúde. Os temperos são cultivados e levados à cozinha pelos jovens, enriquecendo o trabalho das oficinas de nutrição que ocorrem no local.

Em fevereiro de 2012 as ações da Naturologia e do Laboratório Horta na Casa do Adolescente de Pinheiros, foram visitadas por alunos norte-americanos do programa Health \& Community - International Honors Program, da Santa Casa de Misericórdia de São Paulo e em novembro do mesmo ano por Equipe de profissionais da OPAS de diversos países da América Latina.

Em todos os três campos de atuação citados, os adolescentes fazem acompanhamento individual regular com o Naturólogo, complementando assim o atendimento médico, psicológico ou nutricional, visando qualidade de vida, autoconsciência e, consequentemente, menores custos futuros com problemas de saúde. Além disso, são trabalhados grupos temáticos onde estão inseridas práticas de yoga, meditação, aromaterapia, florais, percepção corporal, dentre outras Práticas Integrativas e Complementares, inclusive com populações específicas como, por exemplo, a contribuição para grupos de cuidado perinatal e com o bebê (shantala, técnicas de massagem, relaxamento de percepção do corpo).

Realizamos mais de 3.500 atendimentos individuais em naturologia ao longo deste período de 5 anos e mais de 480 grupos com a participação de temas da naturologia. Verificamos ao longo do trabalho que há uma ótima adesão aos tratamentos e à participação dos adolescentes nos grupos de Naturologia, resultados publicados em diversos congressos, dentre eles "World Congress in Pediatric and Adolescent Gynecology, 2010 "; "XII Congreso Latinoamericano De Obstetricia Y Ginecología De La Infancia Y Adolescencia Y VII Congreso Chileno De Obstetricia Y Ginecologia Infantil Y De La Adolescencia, 2011"; “Congresso Internacional de Saúde da Criança e do Adolescente, 2012".

Há uma parceria com a Universidade, onde, semestralmente, estudantes de Naturologia cumprem horas de estágio Hospitalar e Ambulatorial. São 3 supervisores com 7 estagiários no Hospital das Clinicas, 3 na Casa do Adolescente de Pinheiros e 3 no Hospital Pérola Byington.

Relato de experiência: PORTELLA, Caio Fábio Schlechta. 


\section{ANEXO VII \\ (ANAIS DOS CONGRESSOS DE NATUROLOGIA)}

\section{2 - V Congresso Brasileiro de Naturologia}

Disponível em: <http://www.apanat.org.br/_upload/repository/anais12.pdf>

C75 V Congresso Brasileiro de Naturologia (4.: 2012 out. 25-28: Florianópolis - SC).

Anais [do] V Congresso brasileiro de naturologia. III Fórum conceitual de Naturologia / comissão organizadora Kalil Mondadori ... [et al.]. Florianópolis, 2012.

$101 \mathrm{p} . ; 21 \mathrm{~cm}$

1. Promoção da saúde. 2. Natureza - Poder de cura. 3. Saúde. 4. Plantas medicinais. I. Mondadori. Kalil CDD (21.ed.) 615.5

\section{1 - IV Congresso Brasileiro de Naturologia}

Disponível em: <http://www.apanat.org.br/_upload/repository/Cursoseeventos/ANAIS\%20IV\%20CONBRA-

NATU.pdf>

C75 Congresso Brasileiro de Naturologia (4.: 2011 out. 28-30: São

Paulo - SP).

Anais [do] IV Congresso brasileiro de naturologia. II

Fórum conceitual de naturologia / comissão organizadora

Flavia Placeres... [et al.]. São Paulo, 2011.

90 p. $; 21 \mathrm{~cm}$

1. Promoção da saúde. 2. Natureza - Poder de cura. 3.

Saúde. 4. Plantas medicinais. I. Placeres, Flavia.

CDD (21.ed.) 615.5

\section{9 - II Congresso Brasileiro de Naturologia}

Disponível em: <http://www.apanat.org.br/_upload/repository/anais.pdf >

C75 Congresso Brasileiro de Naturologia (2. : 2009 nov. 5-7 : Florianópolis, SC).

Anais [do] II Congresso brasileiro de naturologia. II Encontro do programa linha verde. Fórum conceitual de naturologia / comissão organizadora Patrícia Kozuchovski Dare ... [et al.]. - Palhoça : Ed. Unisul, 2009.

90 p. $; 21 \mathrm{~cm}$

1. Promoção da saúde. 2. Natureza - Poder de cura. 3. Saúde. 4. Plantas medicinais. I. Dare, Patrícia Kozuchovski. II. Título.

CDD (21. ed.) 615.5 


\section{ANEXO VIII \\ (CARTA PEDRA BRANCA DO V CONGRESSO BRASILEIRO DE NATUROLOGIA)}

\section{CARTA DA PEDRA BRANCA}

Palhoça (SC), 28 de Outubro de 2012.

Aos naturólogos, acadêmicos de Naturologia, gestores municipais, estaduais, federais; instituições formadoras nos campos da Educação, Ciência \& Tecnologia; redes e movimentos sociais, população em geral; organizações, pesquisadores, docentes e profissionais de saúde:

Reunidos no V CONGRESSO BRASILEIRO DE NATUROLOGIA - CONBRANATU, entre 25 e 28/10/2012, no Campus Norte - Pedra Branca da Universidade do Sul de Santa Catarina - UNISUL, os congressistas debateram resultados de pesquisa e experiências relacionadas à Naturologia e às Práticas Integrativas e Complementares. Foram discutidos os desafios, avanços e as perspectivas relativas ao campo da Naturologia no âmbito científico, do reconhecimento e da regulamentação da profissão. O Congresso sediou também o Fórum Conceitual, cujas reflexões visaram a consolidação da prática naturológica, a partir da discussão de questões fundamentais sobre as bases na Naturologia, lapidando e aprofundando a identidade do naturólogo como terapeutas, enfatizada sua atuação igualmente para educação em saúde.

No âmbito das associações de Naturologia, discutiu-se a importância da adesão pelos acadêmicos e naturólogos. Com o objetivo de fortalecimento da classe, no congresso de Naturologia de 2011 acordou-se a fusão da Associação Brasileira de Naturologia e Associação Paulista de Naturologia, a qual encontra-se em vias de efetivação.

Na pesquisa, salientou-se a importância do incentivo aos naturólogos para ingressarem em mestrado e doutorado, da busca por fomentos externos e por fortalecimento das publicações na área, somando esforços com a "Revista Cadernos de Naturologia e Terapias Complementares". Discutiu-se também a necessidade de criação de grupos de trabalhos e agenda de pesquisa da área.

No ensino, os congressistas consideraram de extrema importância a criação de novos cursos de graduação em Naturologia no Brasil, tanto no âmbito público quanto no privado, notadamente a possível criação do curso de Naturologia na Universidade Federal do Paraná - Campus Litoral. Ressalta-se, igualmente, o fortalecimento das graduações já existentes nos seguintes aspectos: ampliação da divulgação da Naturologia; incentivo aos intercâmbios entre as universidades brasileiras e outras instituições estrangeiras com afinidade e experiências com Práticas Integrativas e Complementares; oferecimento de cursos de atualização em Naturologia.

No nível de Pós-Graduação, sublinha-se a relevância da formulação de cursos de Atualização, Aperfeiçoamento, Especialização e Mestrado nas áreas de Naturologia e afins. Quanto ao processo de classificação da ocupação de naturólogo, esclareceu-se que está em sua fase final. Concernente à regulamentação da profissão (projeto de lei 3804/12), foi dito que, neste ano, o projeto de lei foi apresentado e encontra-se em tramitação. Em relação a este tema, debateu-se a necessidade de organização de um grupo de trabalho de assessoria parlamentar no intuito de acompanhamento do trâmite, esclarecimento dos parlamentares quanto à profissão $\mathrm{e}$ mediação entre os naturólogos e o poder legislativo, além da produção de abaixo-assinado para fortalecimento por meio de uma petição pública.

Os participantes do congresso reforçaram a vocação naturológica para o cuidado e promoção da saúde, em todos os âmbitos, mas, muito especialmente, nos serviços de saúde, nas diferentes redes de atenção. Para que a atuação naturológica seja ampliada e sedimentada, identifica-se como questão estratégica a abertura de concursos públicos para naturólogos. Percebe-se que a divulgação, a mais ampla possível, destes editais também é fundamental, inclusive para mapeamento dos locais do país onde haja naturólogos concursados.

A utilização das redes sociais, das instituições formadoras e das associações exerce papel de destaque em todos os processos acima propostos. Os congressistas afirmaram que o mérito das discussões conflui para o acesso amplo e democrático das práticas integrativas e complementares à população em geral, em que os naturólogos têm importante papel.

\section{ASSOCIAÇÃO BRASILEIRA DE NATUROLOGIA - ABRANA ASSOCIAÇÃO PAULISTA DE NATUROLOGIA - APANAT}

Disponível em: <http://apanat.org.br/noticias/noticias/carta-de-pedra-branca/> 